\title{
The Remaining Useful Life Estimation of Lithium-ion Battery Based on Improved Extreme Learning Machine Algorithm
}

Jing Yang ${ }^{1,2,3}$, Zhen Peng ${ }^{4}$, Hongmin Wang ${ }^{1,2,3}$, Huimei Yuan ${ }^{1,2,3}$, Lifeng $\mathrm{Wu}^{1,2,3^{*}}$

${ }^{1}$ College of Information Engineering, Capital Normal University, Beijing 100048, China;

${ }^{2}$ Beijing Key Laboratory of Electronic System Reliability Technology, Capital Normal University, Beijing 100048, China

${ }^{3}$ Beijing Advanced Innovation Center for Imaging Technology, Capital Normal University, Beijing 100048, China

${ }^{4}$ Information Management Department, Beijing Institute of Petrochemical Technology, Beijing 10217 , China

*E-mail: wulifeng@cnu.edu.cn

doi: $10.20964 / 2018.05 .84$

Received: 31 January 2018 / Accepted: 11 March 2018 / Published: 10 April 2018

In order to predict the remaining useful life (RUL) of lithium-ion battery more accurately, a new prediction method based on extreme learning machine (ELM) is proposed in this paper. First, according to the mutation idea of genetic algorithm (GA), we add mutation factors to improve particle swarm optimization (PSO) algorithm. Then, the particles generated by the improved PSO algorithm are used as the input weights and bias of the ELM algorithm. The optimized ELM prediction model is applied to estimate the RUL of the lithium-ion battery. Three sets of data are used to verify the accuracy of the proposed algorithm in this paper.

Keywords: Lithium-ion battery; RUL; ELM; PSO; Mutation factor

\section{$\underline{\text { FULL TEXT }}$}

(C) 2018 The Authors. Published by ESG (www.electrochemsci.org). This article is an open access article distributed under the terms and conditions of the Creative Commons Attribution license (http://creativecommons.org/licenses/by/4.0/). 